\title{
Green Development Assessment of Smart city Based on PP-BP Intelligent Integrated and Future Prospect of Big Data
}

\author{
Chen $\mathrm{li}^{1}$, Wangchenxuan ${ }^{2}$ \\ ${ }^{1}$ Anhui Jianzhu University, Hefei, China Email: chinalichina@163.com \\ ${ }^{2}$ Guilin University Of Electronic Technology, Guilin , China Email: chinaxuanchina @163.com
}

This is an open access article distributed under the Creative Commons Attribution License, which permits unrestricted use, distribution, and reproduction in any medium, provided the original work is properly cited.

\section{ARTICLE DETAILS}

ABSTRACT

\section{Article history:}

Received 12 August 2016 Accepted 12 December 2016 Available online 20 January 2017

\section{Keywords:}

Smart city, Green Development Assessment, PP-BP Intelligent Integrated, Big Data
Smart city is a new information technology to promote the new concept and mode of urban planning, construction, management and service, such as internet of things, cloud computing, big data, spatial geographic information integration, and so on, and it has become an irreversible historical trend in the development of the world city. Domestic research on smart city has become a hot spot, especially for the green development of smart city. This paper attempts to use some indicators that can fully reflect the green development characteristics of smart city, comprehensive, objective and comprehensive evaluation, the index system should follow the principles that is comprehensive, scientific principles, key principles, comparability principle, feasibility principle. Using the method of projection pursuit BP intelligent integration, the green development of smart city is evaluated. The empirical results of smart city green development assessment show that the top three are Guangdong, Shandong and Jiangsu province respectively.

\section{SMART CITY CONCEPT AND DEVELOPMENT AT DOMESTIC AND ABROAD}

The smart city is a new concept and model for the wisdom of urban planning, construction, management and service by using new generation information technology such as IOT, cloud computing, large data and spatial geographic information integration. Nowadays, "smart city" has been born in the course of transformation from "Digital Earth" to "smart earth". The world will continue to "shrink", "flatten" and "being wisdom", and human beings are entering an era of global integration, a circumstance of intelligent economy, sociality and Earth. With the progression of urbanization in China, the concept of smart city is becoming more approachable, tangible and comprehensible. With the development of information technology and stimulation of the application of urban informationization the construction of smart city has emerged. The construction of smart city is continuing to be accelerated, and the national experimental Intelligent Urban construction has been expanded in several years.

The Construction of smart city has been explicitly proposed in the Thirteenth Five-Year Plan, and was in further progress. There are 290 cities has been selected as national pilot smart city, and more than 300 cities achieved smart city construction agreements with local enterprises. Due to integrated usage of new generation of information technology, including radio frequency sensing technology, cloud computing technology, next generation of communication technology, smart city is capable to effectively solve the "urban disease" problem. The application of these technologies can make the city more easily perceived, the city assets more easily integrated. On the basis of this, refined and intelligent management of cities can be achieved, so as to reduce resource consumption, reduce environmental pollution, solve traffic congestion, eliminate security risks, and ultimately achieve the sustainable development of the city ${ }^{[1]}$.

The study of the smart city, which can be traced back to 1980s, was first exemplified by Manuel Castell and his "Information Age Trilogy", and
Western geography community began to investigate the intrinsic relation between information technology and urban development. However, the Western geographers mainly focused on the relationship between technology and society, rather than special consideration of urban morphology. The first appearance of the "smart city" was in the organization of the industrial technology association, named after a smart city in Las Vegas in 1984. The American administration issued a reference to the "international information base implementation" document in 1993. The American administration in the State of the Union address explicitly put forward the "information superhighway" spread the whole country, which opened the prelude to the smart city construction in United States. At present, more than 50 countries and regions have planed the pilot and demonstration projects of smart cities, which combines the construction of smart cities with urban economic development, industrial revitalization, public service and social governance improvement, meanwhile formulates corresponding national development strategies ${ }^{[2]}$.

The construction of smart city has just started in China, many cities are actively promoting the smart city construction. In April 2012, Chinese Academy of Engineering announced Beijing, Xi'an, Hangzhou, Wuhan, Ningbo as the "Chinese smart city" pilot cities, and the implementation of strategic deployment such as "convergence", "five simultaneous" and "three-network fusion", which utilize the latest technologies such as IOT, cloud computing, broadband network technology to promote the construction and development of smart city. It becomes the main concept of urban informationization construction in China. Nowadays, China has released three batches of smart city pilot list.

The domestic smart city is in the stage of development, due to Chinese national conditions, the smart city of China is supposed to be discussed from different aspects, and the construction of the index system of Smart city is more concerned with the hard strength index of the technology development and application of smart city and the infrastructure construction. From a technical perspective, Wu Hequan identifies the Smart city as the Network City, so the IOT is its important symbol. Moreover, Li Deren adds his detailed description: Smart city=Digital city 
+ IOT+ cloud computing. However, one cannot blindly consider the construction of smart city from merely a technical standpoint, Wang Shiwei (2010) suggests in his research of infrastructure construction, the foundation of it are digital, networked and intelligent information technology facilities; the core elements are society, environment and management; the main features are ubiquity, environmental protection, and benefit the people. While emphasizing "informationization" and "infrastructure" construction, various cities have different development strategies based on their own economy, sociality, space, and technology and other conditions ${ }^{[3]}$.

Rapid urbanization has raised many challenges to Chinese cities, and the "urban disease" in some area became increasingly severe to deal with. In order to solve this problem of urban development, to achieve urban sustainable development, it is necessary to realize the construction of Smart city has become an irreversible historical trend of urban development in today's world. The study of smart city in China has become a hotspot, especially for the development of Smart city in an environmental friendly manner.

This paper evaluates the green development of Smart city by using the method of projection pursuit- backpropogation (That is PP-BP) intelligence integration.

\section{METHOD OF PP-BP INTELLIGENCE INTEGRATION \\ A..Concept of PP Method}

PP method belongs to the exploratory data analysis method which is directly driven by the sample data. It uses the projection index function $(\mathrm{z}(\mathrm{i}))$ to describe the probability of projective projection to the structure of the projection to the low dimensional subspace through some combination projection to the configuration child (i), and then analyzes the classification structure features of high dimensional data, such as the projection pursuit cluster evaluation model, or constructs the appropriate mathematical model according to the projection value and the actual output value of the system Projection pursuit model is as follow.

Taking the $\mathrm{j}$ indicator of the sample $\mathrm{i}$ as $\boldsymbol{x}_{i}(i=1,2, \ldots, \eta j j=1,2 ; \cdot, n) \quad \mathrm{n}$ as the number of samples and $\mathrm{m}$ as the number of indicators, the steps of constructing the projection pursuit cluster model by projection pursuit are as follows. Normalization of sample index data. Since the dimensions of each index are different or different, the data is normalized before modeling $x_{i j}^{\prime}=x_{i j} / x_{j \max }$, which represents the $j$ maximum value of the sample of the first index. Linear projection

2. The so-called projection is to observe the data from different angles, in order to find the best projection direction which can fully excavate the data characteristics. Several initial projection directions can be selected randomly in the unit super , the projection index size is calculated, and according to the principle of selecting big indexes, the solution of the maximum index is determined as the optimal projection direction.

If the unit vector $a\left(a_{1}, a_{2}, \cdots, a_{m}\right)$, the projection eigenvalues $Z_{\mathrm{i}}$ of sample i in one-dimensional linear space are expressed

$$
z_{i}=\sum_{j=1} a_{j} x_{i j}^{\prime} .
$$

3. Looking for the target function

When the value of the comprehensive projection index value, the dispersion characteristic of the projection value should be the local projection point is as dense as possible, it is best to agglomerate into several point, and scatter as much as possible in the whole projection point

group. Therefore, the objective function $Q(a)$ can be

defined as the product of between distance $s(a)$ and within density $d(a)$, i. e.

$Q(s)=s(a) \cdot d(a)$

4. The direction of optimizing the projection: from the above analysis, the projection direction corresponding to

the maximum value $Q(a)$ is the optimal projection direction to be sought. Therefore, the problem of finding the optimal projection direction can be translated into the following optimization problems:

$$
\left\{\begin{array}{c}
\max Q(a)=s(a) \cdot d(a) \\
\|a\|=\sum_{j=1}^{m} a_{j}^{2}=1
\end{array}\right.
$$

This is a complex nonlinear optimization problem for optimizing variables $a_{\mathrm{j}}$.

5. Comprehensive evaluation analysis

According to the optimal projection direction, the difference level of the projection characteristic value $Z$ reflecting the comprehensive information of each evaluation index can be calculated $d^{[4]}$.
B.Method of $B P$

Artificial neural network, which is based on the research of modern neurology, biology, psychology and others, has been widely used in many fields such as speech analytics, image recognition, digital watermarking, computer vision, and has resulted many outstanding achievements.The advantages of BP neural network as followings.1 ) Nonlinear mapping ability.BP neural network essentially practices a mapping function from input to output, and mathematical theory proved that the neural network of three layers can approach any nonlinear continuous function with arbitrary accuracy. This makes it particularly suitable for solving the internal mechanistic complex problem, namely BP neural network has strong nonlinear mapping ability. 2 ) Self-learning and adaptive ability. BP neural network can automatically extract the reasonable rules between the output and output data through learning, and adapt the learning content to the network's weight. The BP neural network has the ability of highly selfstudy and adaptive. 3 ) Generalization ability. the so-called generalization ability refers to the design pattern classifier, that is to consider the network to ensure correct classification of the required classification objects, but also care about the network after training, whether the model or the mode of noise pollution, correct classification. The BP neural network has the ability to apply learning results to new knowledge. 4 ) Fault tolerance. BP neural network will not affect the global training results after the local or partial neuron damage is damaged, which means that the system can work normally even if the system is injured partially. That is, the BP neural network has certain fault tolerance ability. The process of BP algorithm is as following ${ }^{[5]}$.

Set each right value and the initial value $w_{j i}^{(l)}[0]$ of the threshold, $\theta_{j}^{(l)}[0](l=0,1, \ldots, L)$ for the small random number.

Input the training sample $I_{q}, d_{q}$ ), carry on ( 3 ) to ( 5 ) step for each sample.

calculate the actual output of each network layer

$x^{(l)}=f\left(s^{(l)}\right)=f\left(w^{(l)} x^{(l-1)}+\theta^{(l)}\right)$

Calculation of training error

$\partial_{j}=\left(d_{q j}-x^{(l)}\right) f\left(s_{j}^{(l)}\right)$,Output layer

$\partial_{j}^{(l)}=f^{\prime}\left(s_{j}^{(l)}\right) \sum_{k=1}^{n_{k+1}} \partial^{(1+p)} w_{k j} \quad$, Hidden layer and input layer

Modify positive weight and threshold

$$
\begin{gathered}
w_{j i}^{(l+1)}[k+1]=w_{j i}^{(l)}[k]+\mu \partial_{j}{ }^{(l)} x_{i}^{(l-1)}+\eta\left(w_{j i}^{(l)}[k]-w_{j i}^{(l)}[k-1]\right) \\
\left.\theta_{j}^{(l+1)}[k+1]=\theta_{j}^{(l)}[k]+\mu \partial_{j}{ }^{(3)}+\eta(\phi)[k]-\theta_{j}^{(l)}[k-1]\right)
\end{gathered}
$$

(6) When all the samples in the sample set have gone through ( 3 ) ( 5 ), an epoch is completed, and the performance $\mathrm{i} \quad \stackrel{Q}{\mathrm{E}=}=\sum_{q=1} \mathrm{E}_{q} \quad$ is
calculated

$$
\mathrm{E}_{q}=\frac{1}{2} \sum_{j=1}^{m}\left(d_{q j}-x_{q j}\right)^{2}
$$

( 7 ) If the performance indicator meets the accuracy requirements, that is $\mathrm{E} \leq \varepsilon$, the training ends, otherwise, go to ( 2$)$ and continue the next training cycle.

\section{ASSESSMENT OF SMART CITY GREEN DEVELOPMENT BASED ON PP-BP}

\section{A.Construction of Indicator System}

This paper attempts to use some indicators that can fully reflect the green development characteristics of smart city, comprehensive, objective and comprehensive evaluation, the index system should obey the following principles: comprehensive principles, scientific principles, significance principles, comparability principle, and feasibility principle. Based on the actual situation of smart city green development in China, this paper analyzes the connotation, characteristics and representativeness of sample data, and summarizes the connotation of smart city, including that general industrial solid waste, comprehensive utilization of industrial solid waste, harmless disposal rate ( $\%)$, forest cover rate, total grassland area, wetland area ( \%), natural reserve area (ten thousand hectares ), area of soil and water loss (thousand hectares), green area cover rate ( $\%)$, cleaning and maintenance area (ten thousand square meter) and household garbage disposal. 


\begin{tabular}{|c|c|c|c|c|c|}
\hline Sample & $\begin{array}{c}\text { general } \\
\text { industri } \\
\text { al solid } \\
\text { waste }\end{array}$ & $\begin{array}{c}\text { comprehensive } \\
\text { utilization of } \\
\text { industrial solid } \\
\text { waste }\end{array}$ & $\begin{array}{c}\text { harmless } \\
\text { disposal rate } \\
\text { (\%) }\end{array}$ & $\begin{array}{c}\text { forest } \\
\text { cover } \\
\text { rate (\%) }\end{array}$ & $\begin{array}{c}\text { total } \\
\text { grasslan } \\
\text { darea }\end{array}$ \\
\hline shangh & 592 & 7.59 & 78.8 & 35.84 & 394.8 \\
\hline beijing & 1524 & 3.15 & 92.7 & 9.87 & 146.6 \\
\hline tianjin & 19900 & 36.32 & 96.0 & 23.41 & 4712.1 \\
\hline jiangsu & 17617 & 12.95 & 97.2 & 18.03 & 4552.0 \\
\hline shangd & 12306 & 90.75 & 97.7 & 21.03 & 78804.5 \\
\hline zhejian & 10029 & 19.96 & 95.2 & 38.24 & 3388.8 \\
\hline liaonin & 2986 & 52.42 & 84.7 & 40.38 & 5842.2 \\
\hline chongq & 4308 & 8.71 & 78.2 & 43.16 & 7531.8 \\
\hline fujian & 1796 & 25.77 & 100.0 & 10.74 & 73.3 \\
\hline hubei & 10207 & 127.76 & 100.0 & 15.80 & 412.7 \\
\hline guangd & 4263 & 75.00 & 99.2 & 59.07 & 3169.9 \\
\hline anhui & 11763 & 64.51 & 99.6 & 27.53 & 1663.2 \\
\hline henan & 3784 & 12.05 & 99.2 & 65.95 & 2048.0 \\
\hline hainan & 6152 & 57.67 & 94.5 & 60.01 & 4442.3 \\
\hline jingxi & 18309 & 607.07 & 100.0 & 16.73 & 1638.0 \\
\hline beibei & 11456 & 29.70 & 96.0 & 21.50 & 4433.8 \\
\hline hunan & 5253 & 21.15 & 91.5 & 38.40 & 6352.2 \\
\hline shanxi & 4683 & 221.81 & 99.8 & 47.77 & 6372.7 \\
\hline cichua & 5103 & 75.30 & 91.6 & 51.26 & 3266.2 \\
\hline shanxi & 4388 & 71.89 & 98.7 & 56.51 & 8698.3 \\
\hline guangx & 268 & 0.12 & 99.8 & 55.38 & 949.8 \\
\hline
\end{tabular}

\begin{tabular}{|l|c|c|c|c|c|}
\hline jilin & 2424 & 25.04 & 98.6 & 38.43 & 2158.4 \\
\hline
\end{tabular}

\begin{tabular}{|c|c|c|c|c|c|}
\hline heilon & 5507 & 59.08 & 96.8 & 35.22 & 20380.4 \\
\hline neimen & 4289 & 30.30 & 93.8 & 37.09 & 4287.3 \\
\hline
\end{tabular}

\begin{tabular}{|c|c|c|c|c|c|}
\hline neimen & 4289 & 30.30 & 93.8 & 37.09 & 4287.3 \\
\hline ningxi & 7198 & 110.13 & 90.0 & 50.03 & 15308.4 \\
\hline
\end{tabular}

\begin{tabular}{|c|c|c|c|c|c|}
\hline yunnan & 12 & 110.13 & 90.0 & 11.98 & 82051.9 \\
\hline
\end{tabular}

\begin{tabular}{|c|c|c|c|c|c|}
\hline yuizho & 6102 & 11.74 & 98.0 & 41.42 & 5206.2 \\
\hline
\end{tabular}

\begin{tabular}{|c|c|c|c|c|c|}
\hline xizhan & 3079 & 19.87 & 64.2 & 11.28 & 17904.2 \\
\hline
\end{tabular}

\begin{tabular}{|c|c|c|c|c|c|}
\hline xinjian & 7247 & 139.47 & 87.2 & 5.63 & 36369.7 \\
\hline ingh & 2131 & 5.53 & 89.9 & 11.89 & 3014.1 \\
\hline
\end{tabular}

\begin{tabular}{|l|l|l|l|l|l|l|}
\hline qingha & 2131 & 5.53 & 89.9 & 11.89 & 3014.1 \\
\hline
\end{tabular}

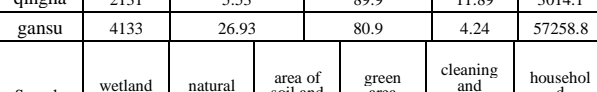

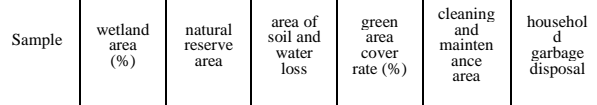

\begin{tabular}{c|c|c|c|c|c|c|}
\hline shangh & 2.86 & 13.4 & 710.8 & 48.4 & 15122 & 790.3 \\
\hline
\end{tabular}

\begin{tabular}{|c|c|c|c|c|c|c}
\hline beijing & 23.94 & 9.1 & 97.3 & 36.4 & 11769 & 240.7 \\
\hline
\end{tabular}

\begin{tabular}{c|c|c|c|c|c|c|}
\hline tianjin & 5.04 & 70.0 & 5061.5 & 41.2 & 26358 & 635.9 \\
\hline$j$
\end{tabular}

\begin{tabular}{|c|c|c|c|c|c|c|}
\hline jiangsu & 0.97 & 110.3 & 5846.4 & 40.1 & 16083 & 447.0 \\
\hline
\end{tabular}

\begin{tabular}{|c|c|c|c|c|c|c|}
\hline shangd & 5.08 & 1271.0 & 12597.2 & 39.2 & 19799 & 329.1 \\
\hline
\end{tabular}

\begin{tabular}{|c|c|c|c|c|c|c|}
\hline zhejian & 9.42 & 275.4 & 4857.8 & 40.3 & 36637 & 933.2 \\
\hline liaonin & 5.32 & 252.5 & 1793.5 & 36.1 & 16957 & 490.3 \\
\hline
\end{tabular}

\begin{tabular}{|c|c|c|c|c|c|c|}
\hline chongq & 11.31 & 750.2 & 3834.2 & 35.8 & 23484 & 523.0 \\
\hline
\end{tabular}

\begin{tabular}{|c|c|c|c|c|c|c|}
\hline fujian & 73.27 & 13.6 & 1834.2 & 38.5 & 17366 & 613.2 \\
\hline
\end{tabular}

\begin{tabular}{|c|c|c|c|c|c|c|}
\hline hubei & 27.51 & 53.0 & 893.8 & 42.8 & 57992 & 1456.1 \\
\hline
\end{tabular}

\begin{tabular}{|c|c|c|c|c|c|c|}
\hline guangd & 10.91 & 20.0 & 3655.4 & 40.6 & 39195 & 1332.6 \\
\hline
\end{tabular}

\begin{tabular}{|c|c|c|c|c|c|c|}
\hline anhui & 7.46 & 45.8 & 1857.4 & 41.2 & 29216 & 491.9 \\
\hline
\end{tabular}

\begin{tabular}{|c|c|c|c|c|c|c|}
\hline henan & 7.18 & 44.5 & 3399.3 & 43.0 & 14881 & 608.1 \\
\hline hainan & 5.45 & 122.6 & 5577.9 & 44.1 & 14019 & 329.3 \\
\hline
\end{tabular}

\begin{tabular}{c|c|c|c|c|c|c}
\hline jingxi & 11.07 & 111.9 & 3776.7 & 42.3 & 68631 & 1377.5 \\
\hline
\end{tabular}

\begin{tabular}{|c|c|c|c|c|c|c|}
\hline beibei & 3.76 & 74.1 & 3559.8 & 37.7 & 29490 & 891.8 \\
\hline & 7.77 & 105.0 & 56343 & 37.5 & 3304 & 83.2 \\
\hline
\end{tabular}

\begin{tabular}{|c|c|c|c|c|c|c|}
\hline hunan & 7.77 & 105.0 & 5634.3 & 37.5 & 33304 & 832.2 \\
\hline
\end{tabular}

\begin{tabular}{|c|c|c|c|c|c|c|}
\hline shanxi & 4.81 & 130.9 & 3259.8 & 39.7 & 19979 & 638.2 \\
\hline
\end{tabular}

\begin{tabular}{|c|c|c|c|c|c|c|}
\hline cichua & 9.76 & 184.9 & 1457.5 & 41.4 & 92161 & 2320.4 \\
\hline
\end{tabular}

\begin{tabular}{|c|c|c|c|c|c|c|}
\hline shanxi & 3.20 & 141.9 & 2107.3 & 37.6 & 18189 & 385.5 \\
\hline guangx & 9.14 & 270.7 & 74.6 & 37.7 & 5289 & 160.1 \\
\hline
\end{tabular}

\begin{tabular}{|c|c|c|c|c|c|c}
\hline jilin & 2.51 & 82.7 & 3070.0 & 40.3 & 15313 & 440.0 \\
\hline
\end{tabular}

\begin{tabular}{|c|c|c|c|c|c|c|}
\hline heilon & 3.61 & 828.6 & 8510.3 & 38.7 & 30196 & 823.6 \\
\hline
\end{tabular}

\begin{tabular}{|c|c|c|c|c|c|c|}
\hline neimen & 1.19 & 89.3 & 6297.8 & 35.9 & 7098 & 268.3 \\
\hline ningxi & 1.43 & 287.3 & 8074.4 & 37.3 & 16769 & 371.0 \\
\hline
\end{tabular}

\begin{tabular}{|l|l|l|l|l|l|l|l|}
\hline & 1.19 & 89.3 & 629.8 & 35.9 & 708 & 268.3 \\
\hline
\end{tabular}

\begin{tabular}{|c|c|c|c|c|c|c|}
\hline guizho & 1.50 & 113.1 & 7288.3 & 40.6 & 15884 & 522.7 \\
\hline
\end{tabular}

\begin{tabular}{|c|c|c|c|c|c|c|}
\hline xizhan & 3.73 & 916.8 & 7702.2 & 30.2 & 8294 & 262.7 \\
\hline
\end{tabular}

\begin{tabular}{|c|c|c|c|c|c|c|}
\hline xinjian & 11.27 & 2166.5 & 898.7 & 29.8 & 2699 & 82.2 \\
\hline
\end{tabular}

\begin{tabular}{|c|c|c|c|c|c|c|}
\hline qingha & 4.00 & 53.3 & 2057.2 & 37.9 & 7956 & 132.2 \\
\hline
\end{tabular}

\begin{tabular}{|c|c|c|c|c|c|c|}
\hline gansu & 2.38 & 1957.5 & 1128.9 & 37.5 & 14489 & 380.0 \\
\hline
\end{tabular}

B.Empirical Study of Smart city Green Development Assessment based on PP-BP Intelligent Integrated

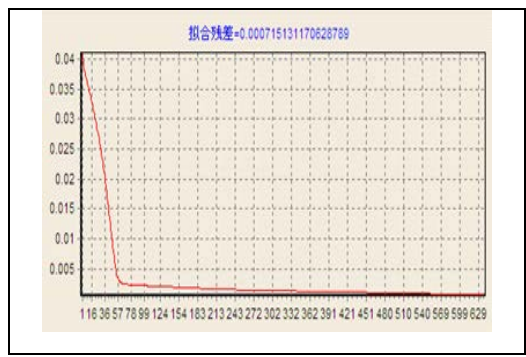

Figure1 BPNeural network training curve

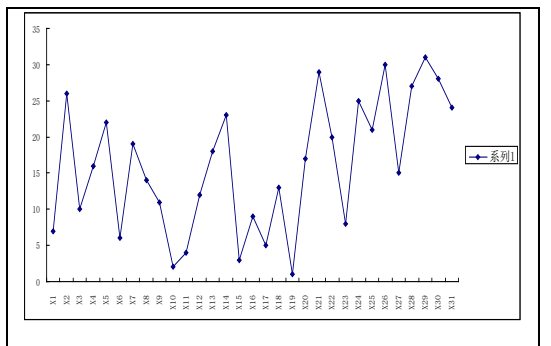

Figure.2 BP neural network runs the results

Table 2 Aggregate Result Ordering

\begin{tabular}{|c|l|l|c|}
\hline Sample & $\begin{array}{l}\text { results of } \\
\text { BP }\end{array}$ & $\begin{array}{l}\text { Results of } \\
\text { Projection } \\
\text { Pursuit }\end{array}$ & $\begin{array}{l}\text { Aggregate } \\
\text { result } \\
\text { ordering }\end{array}$ \\
\hline shanghai & 782.5406 & 14565.1503 & 24 \\
\hline beijing & 240.27 & 11337.7987 & 25 \\
\hline tianjin & 605.3114 & 31184.8982 & 9 \\
\hline jiangsu & 428.2459 & 20253.676 & 14 \\
\hline shangdong & 341.3866 & 23003.6877 & 12 \\
\hline zhejiang & 853.7336 & 37936.5798 & 5 \\
\hline liaoning & 407.3576 & 16060.9174 & 19 \\
\hline chongqing & 492.9481 & 23637.1626 & 11 \\
\hline fujian & 553.4332 & 17084.9775 & 16 \\
\hline hubei & 1188.7375 & 54773.1308 & 3 \\
\hline guangdong & 1141.0615 & 38472.3067 & 4 \\
\hline anhui & 501.5584 & 31370.4876 & 8 \\
\hline henan & 409.8909 & 15283.2546 & 21 \\
\hline hainan & 332.6941 & 15278.0104 & 22 \\
\hline jingxi & 1180.1767 & 72258.3918 & 2 \\
\hline beibei & 674.952 & 32867.1886 & 7 \\
\hline hunan & 929.2475 & 33311.7693 & 6 \\
\hline shanxi & 499.368 & 21476.8945 & 13 \\
\hline cichuan & 2264.4403 & 83603.0411 & 1 \\
\hline shanxi & 412.7487 & 18362.692 & 15 \\
\hline guangxi & 157.613 & 5129.1309 & 30 \\
\hline jilin & 381.6244 & 15418.0713 & 20 \\
\hline heilongjiang & 776.1613 & 30535.8499 & 10 \\
\hline neimeng & 252.7289 & 7785.4412 & 28 \\
\hline ningxia & 373.6568 & 17125.6402 & 18 \\
\hline yunnan & 130.1111 & 5803.3391 & 29 \\
\hline guizhou & 472.0178 & 17068.362 & 17 \\
\hline xizhang & 208.7921 & 9003.4117 & 26 \\
\hline xinjiang & 82.6689 & 5129.1326 & 31 \\
\hline qinghai & 197.8365 & 8185.4144 & 27 \\
\hline gansu & 331.6074 & 15253.0504 & 23 \\
\hline & & & \\
\hline & & \\
\hline
\end{tabular}

\section{CONCLUSION}

The empirical results of smart city green development assessment (Tab.2) show that the top three are Guangdong, Shandong and Jiangsu respectively. Beijing, Shanghai, Tianjin and Chongqing also need to work in the green development of smart cities. The construction of Chinese smart city is mainly focused on construction. For example, like intelligent equipment, intelligent various application software, integrated solution, open platform, integrated services, and so on. In the process of constructing smart city, one should pay attention to green development.

\section{FUTURE PROSPECT OF SMART CITY UNDER BIG DATA}

The construction of smart city is based on the data, if there is no data, data transmission, nor data processing, storage and reuse, not to mention the intelligent management and intelligent construction. The smart city in the future should be the network broadband, management intellectualization, industry high-end and the city of application of information technology, it is the new mode of urban development in the information age. The breakthrough of the concept of cloud computing and a large number of applications, real-time processing, analysis and prediction of the massive data in the real world, and mining new rules can enable people to deal with the various kinds of events in urban production and life. In the construction and application of smart cities, there will be more and more data from $\mathrm{TB}$ to $\mathrm{Pb}$ level, thus entering the era of big data. In 2011, Science journal pointed out that the big data era has come, and the American academy of engineering also pointed out that big data can let us realize the application of mass data in prediction, modeling, 
visualization and discovery of new laws. Intelligent urban under big data is as Fig. 3

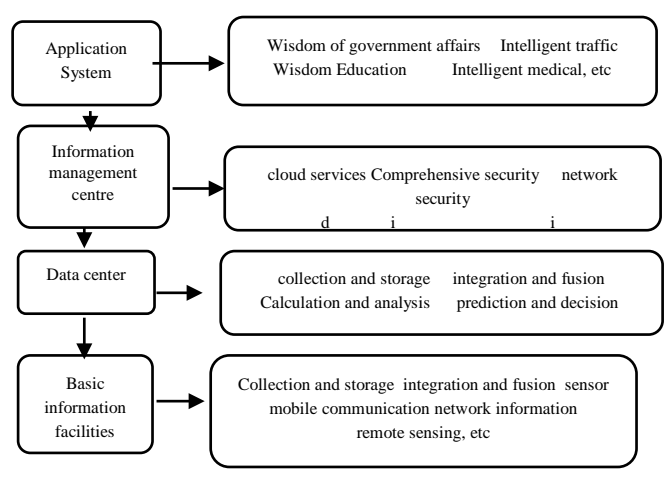

Figure. 3 Intelligent urban under big data

Smart city is the advanced form of city informatization, which utilize new information technology based on the knowledge society in all walks of life based on the knowledge society, facing the social enterprise and the public service platform, reduce the cost of urban information construction and maintenance, intelligent city big data, cloud computing and data mining, to minimize government cost, improve urban efficiency[6].

Basic information infrastructure is the source of vast data in large data, including sensors, cameras, mobile communications, network information, remote sensing, etc. Data center layer is the process of data mining, including data collection and storage, data integration and integration, data calculation and analysis, forecasting and decision making.Center for information services and management, including cloud services and information security two modules, information security, including network security, system security, data security and comprehensive security.Application system layer is in the center of the intelligent platform built on the basis of all kinds of intelligent application system, from the perspective of the government, enterprises and the public, including political wisdom, wisdom, such as traffic, education wisdom, wisdom, health.On the one hand, big data dig deep rely on advanced science and technology, abundant data resources, reasonable planning and design, data collection, processing and utilization of the whole process of development, on the other hand need government organizations set up big data management and sharing platform, for the different government departments, enterprises and residents to provide information ${ }^{[7]}$.

Big data power smart city development, also need government support, wisdom affair cloud platform, implement the data exchange and sharing resources, saving administrative cost, increase the transparency of government affairs and impartiality, enhances the working efficiency of the government, decision-making ability and the ability of public service.

\section{ACKNOWLEDGEMENTS}

Foundation item: The project was financially supported by Study of new-type of urbanization evaluation based on the intelligent integrated optimization of SVM parameters (2015 Natural science fund project in Anhui province, number: 1508085MG144)

\section{REFERENCES}

[1] Wang fengyun, Chen yanan. The intelligent city construction and development dilemma of the big data age. Shanghai city management, vol. 2, pp. 30-35, 2016. Zhang zhengang, zhang [2] xiaojuan. Research and evaluation of intelligent cities. Management modernization, vol. 6, pp. 126-128, 2013.

[3] Gu sheng-resistance: "the 13th five-year" wisdom urban development and economic transformation. China information community, vol. 2, pp. 25-26, 2016.

[4] Miao Jingyi,Yan Xuxian. Evaluation of Region Sustainable Development Based on Projection Pursuit Classification Model-Empirical Analysis Based on 1998-2011 Data of the 30 Provinces.Journal of Industrial Technological Economics, vol. 10, pp. 77-85, 2013.

[5] Zou Kai, Bao Minglin. Evaluation of Smart city Develop Potential Based on Gray Relation Theory and BP Neural Network, Science\&Technology Progress and Policy, , vol. 9, pp. 123-128, 2015.

[6] Wang jingyuan, li chao, xiong zhang, zhiguang. The data center of intelligent urban research review. Computer research and development., vol. 51, pp. 239-25, 2014 .

[7] MARIUSZ JEDLINSKI. The position of green logistics in sustainable development of a smart green city. Procedia Social and Behavioral Sciences. , vol. 151, pp. 102-111, 2014. 